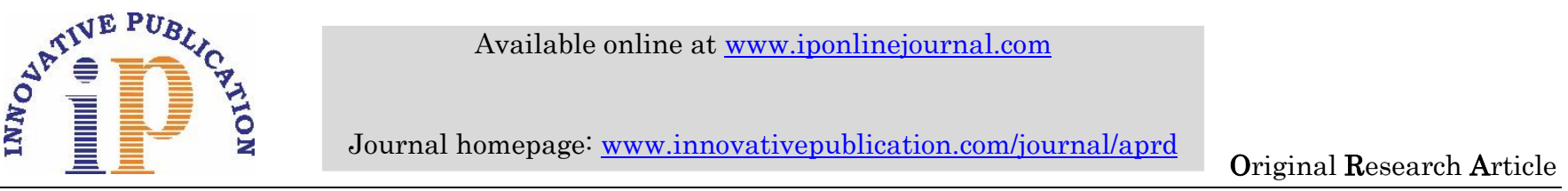

\title{
An analysis of dental treatments rendered by undergradutes at ajman university to patients from fujairah, UAE
}

\author{
Suleiman M Ergieg ${ }^{*}$, Abdulhadi Warreth ${ }^{2}$ \\ ${ }^{1}$ Professor, ${ }^{2}$ Assistant Professor, ${ }^{1}$ Dept. of Paediatric Dentistry, ${ }^{2}$ Dept. of Prosthodontics, Ajman University, UAE
}

\begin{abstract}
Objectives: This study undertaken to highlight the dental treatments delivered by undergraduate students at Ajman University to patients from Fujairah and to examine the relationship between ages, gender, and the types of dental treatments.

Materials and Methods: A total of 650 dental records were selected from 6000 dental records of patients who had received dental treatment in the Dental Clinic, College of Dentistry, Ajman University(AU)-Fujairah Campus, between academicyear,2015/2016 and 2016/2017.

Results: The combination of restorative treatments(composite, amalgam and glass ionomer) adds up to $34.4 \%$, of the total services received by patients, followed by $21.6 \%$ scaling \&polishing, $15.5 \%$ extraction and $13.47 \%$ endodontic procedures. The combination of preventive treatments $4.2 \%$, pediatric treatments, add up to $5.5 \%$ and prosthetic treatments contributed for 5.4\%. Using the SPSS, Regression option. It was found that no significant regression between the gender and the treatments (sign $=0.699$ ), but there was a significant regression between the age and the treatments $(\operatorname{sign}=0.00)$. Chi-square test shows a significant association $($ sign $=0.0)$ between age groups and removable prosthetic dominant at age group (32-44 years). There is, a significant association between age groups, and the following dental treatments: fluoride, fissure sealants, space- maintainer, pulp-therapy, stainless steel crown and glass-ionomers dominant at age group (6-18years).No association between gender \& types of dental treatments.

Conclusion: The study demonstrates the types and amount of dental treatments given to patients from Fujairah by under graduate dental student as part of their clinical training program through, Dental School's clinic, Ajman University- Fujairah campus. Further large-scale study to assess the quality and patients' satisfaction regarding the treatments provided by under graduate students is highly recommended.
\end{abstract}

Keywords: Dental treatments, Dental school's clinic, Undergraduate students.

\section{Introduction}

Dental schools continue to strive for the most effective ways to provide clinical education for the students. In this respect, it is important that each student should gain the necessary experience of routine dentistry both in adults and in children before they qualify and start practicing independently. Both private and public sectors provide oral healthcare, in many countries (Nikolovsk 2013). Colleges of Dentistry both in public and private universities provide free and paid dental treatments to the patients attending their Clinics as part of the students training program (Wanyonyi KL, 2017, Ephrem 2018). In the United Arab Emirates (UAE), both private and public sectors are responsible for providing dental services. College of Dentistry, Ajman University- Fujairah, UAE delivers free dental services as part of the training program for dental students, where the fourth and fifth-year undergraduate students treat patients who have diverse needs. Most of the treatments provided by the dental school are routine dentistry that would usually be provided by a general dentist. A qualified dentist or senior staff always supervises students during their clinical training.

This study is conducted to highlight the aspects of dental treatments delivered by undergraduate students at Ajman University to patients from Fujairah and to examine the relationship between age, gender, and types of dental treatments.

\section{Materials and Methods}

Ethics approval for this research obtained from the institutional ethical review committee, Ajman University (AU). Ref. \#2017-FJ-DN-03. A total of 650 dental records was randomly selected from 6000 dental records of patients who had received dental treatment in the Dental Clinic, College of Dentistry, Ajman University(AU), Fujairah Campus, between the academicyears2015/2016 and 2016/2017. The size of study sample was determined using, Cochran' formula at $95 \%$ confidence. Using the random table generated by Microsoft Excel, the records for 650 patients were then randomly selected. After all the dental records to be included in this study were chosen and retrieved from the achieves. The following types of dental treatments: Composite restorations, amalgam restorations, glass ionomer restorations, fixed prosthetic treatments, removable prosthetic treatment, endodontic treatments, extractions treatments, fluoride treatments, fissure sealants treatment, pulp therapy treatments and stainless steel crowns treatments were extracted from the patient's dental records, coded and recorded in Microsoft excel sheet.

\section{Statistical analysis}

Statistical analyses of the data performed using SPSS 17. The SPSS Regression option was used to examine the 
relation between dental treatments, age, and gender. Chisquare $(\chi 2)$ test at a level of significant $\alpha=0.05$ was also used to determine statistically significant differences between dental treatments, each of the Age Groups, and Gender. Phi- Coefficient was used to test the strength of the association.

\section{Results}

Results obtained from this study are based on the treatment progressive sheet of the patients' records. Females (273) comprised $42 \%$ of the sample and males (377) were $58 \%$. Data on 650 dental patient's records from Microsoft Excel sheet transferred to the Statistical Package of social science (SPSS). Percentages of each type of dental treatment shown in Fig. 1. reveals that $27.59 \%$ of the treatment provided was a composite restoration, followed by $21.61 \%$ scaling and polishing, $15.47 \%$ extractions, 13.47 pulp therapy endodontic treatment and the remaining $21 \%$ includes, amalgam restoration, fixed prosthesis, removal prosthesis, fluoride treatment, fissure sealants, space maintainers, stainless crown and glass-ionomer restorations. The combination of restorative Treatments(composite, amalgam and glass ionomer) adds up to $34.4 \%$, of the total treatment received by patients, followed by $21.6 \%$ scaling \&polishing, $15.5 \%$ extraction and $14.5 \%$ endodontic procedures. The combination of preventive treatments (fluoride\& fissure sealants) add up $4.2 \%$. Pediatric treatments (pulp therapy, space maintainers and stainless steel crown) add up to $5.5 \%$ and prosthetic treatments (fixed \& removable) contributed for $5.4 \%$. Using SPSS, Regression option, it was found that there was no significant regression between gender and the treatments $(\operatorname{sign}=0.699)$. However there was a significant regression between the age and the treatments $(\operatorname{sign}=0.00)$. To know which age group dominant a certain treatment, data regrouped based on age and gender (Table 1). Chisquare test (Table 2) was used. It shows a significant association $(\operatorname{sign}=0.0)$ and it is a moderate $(\mathrm{Phi}=0.0224)$ between age groups and removable prosthetic dominant at age group (32-44 years). There is also a significant association between age groups, dominant at age group (618years), and the following dental Treatments:

1. Fluoride $(\operatorname{sign}=0.0)$ and it is a strong $(\mathrm{Phi}=0.505)$,

2. Fissure Sealants (sign $=0.0)$ and it is a strong (Phi=0.531),

3. Space- maintainer $(\operatorname{sign}=0.0)$ and it is a moderate (Phi $=0.228$,

4. Pulp-therapy $(\operatorname{sign}=0.0)$ and it is a strong $(\mathrm{Phi}=0.511)$,

5. Stainless steel Crown ( $\operatorname{sign}=0.0)$ and it is a strong (Phi $=0.476)$, and

6. Glass-ionomers $($ sign $=0.00)$ and it is a moderate $(\mathrm{Phi}=$ 0.283).

No association between gender \& types of dental treatments (Table 3).

Table 1: Gender and age group

\begin{tabular}{|c|c|c|c|c|c|}
\hline \multirow{2}{*}{ Gender } & \multicolumn{5}{|c|}{ Age Group } \\
\cline { 2 - 6 } & Group 6-18 & Group 19-31 & Group 32-44 & Group 45-57 & Group 58-70 \\
\cline { 2 - 6 } & Count & Count & Count & Count & Count \\
\hline Female & 53 & 119 & 87 & 14 & 0 \\
Male & 71 & 165 & 126 & 11 & 7 \\
\hline
\end{tabular}

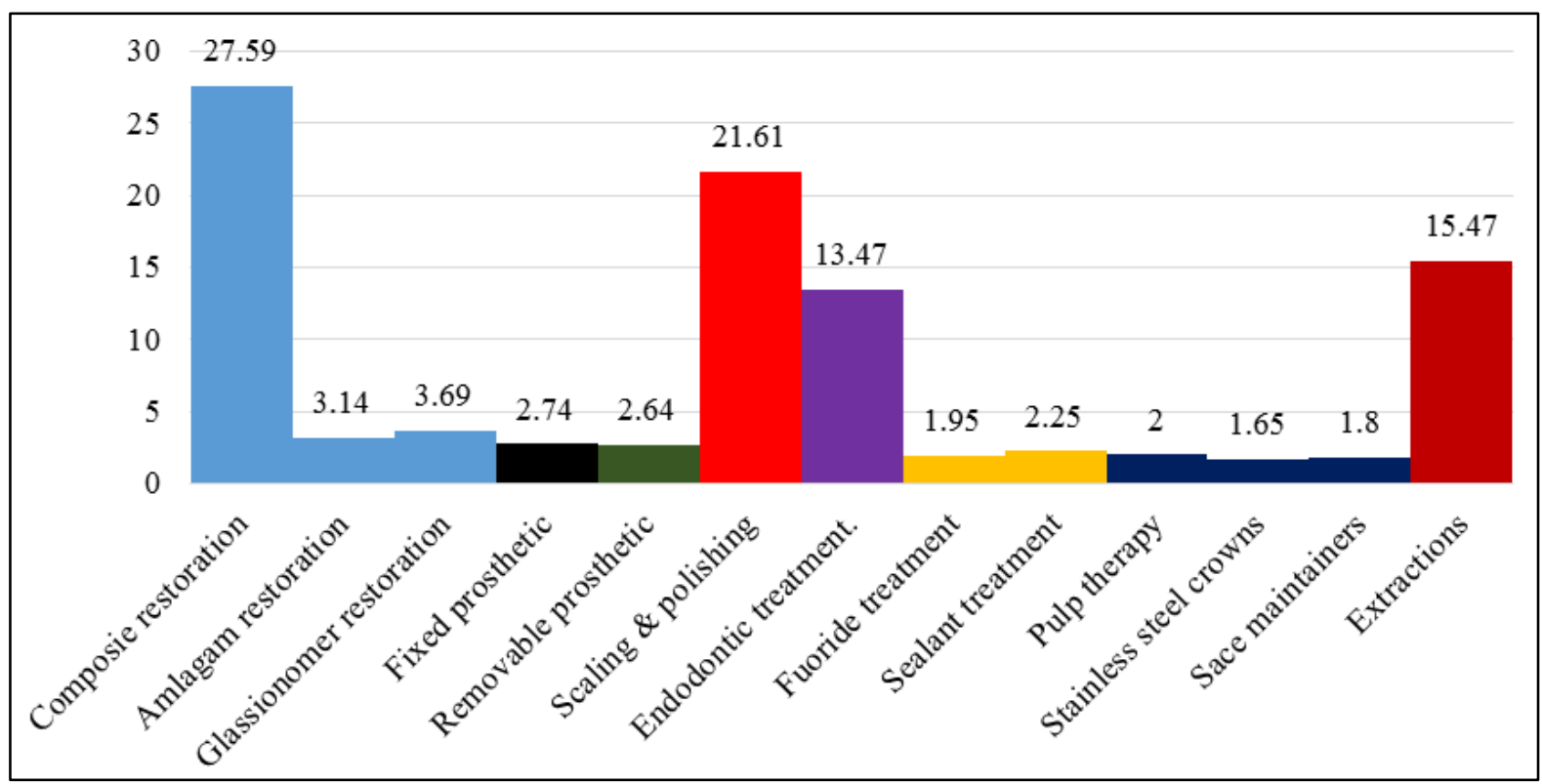

Fig. 1: Percentage of each type of dental treatment. 
Table 2: Chi-square test (Treatments vs age groups)

\begin{tabular}{|c|c|c|c|c|c|c|c|}
\hline \multirow[b]{2}{*}{ Treatment procedure } & \multicolumn{5}{|c|}{ Age Groups } & \multirow[b]{2}{*}{$\begin{array}{c}\text { Chi-square } \\
\text { P-value }\end{array}$} & \multirow[b]{2}{*}{ Phi-value } \\
\hline & 6-18 yrs. & $\begin{array}{c}19-31 \\
\text { yrs. }\end{array}$ & 32-44 yrs. & 45-57 yrs. & $\begin{array}{c}58-70 \\
\text { yrs. }\end{array}$ & & \\
\hline Composite restoration & 19.15 & 43.67 & 32.91 & 3.64 & 0.63 & 0.583 & 0.066 \\
\hline Amalgam Restoration & 12.7 & 39.68 & 41.27 & 4.76 & 1.59 & 0.342 & 0.083 \\
\hline Extraction & 17.74 & 44.19 & 32.9 & 4.84 & 0.32 & 0.589 & 0.066 \\
\hline Fixe prosthetics & 9.09 & 47.27 & 40 & 3.64 & 0.0 & 0.325 & 0.085 \\
\hline Removable Prosthetic & 9.43 & 26.42 & 47.17 & 13.21 & 3.77 & 0.0 & 0.225 \\
\hline Fluoride & 97.44 & 0.0 & 0.0 & 2.56 & 0.0 & 0.0 & 0.505 \\
\hline Fissure sealants & 95.56 & 2.22 & 2.22 & 0.0 & 0.0 & 0.0 & 0.531 \\
\hline Scaling and polishing & 21.02 & 43.19 & 32.56 & 2.77 & 0.46 & 0.134 & 0.104 \\
\hline Space Maintainer & 52.78 & 11.11 & 36.11 & 0.0 & 0.0 & 0.0 & 0.228 \\
\hline Endodontic treatment & 16.3 & 42.96 & 35.56 & 3.7 & 1.48 & 0.07 & 0.116 \\
\hline Pulp therapy & 97.5 & 2.5 & 0.0 & 0.0 & 0.0 & 0.0 & 0.511 \\
\hline Stainless steel crown & 100 & 0.0 & 0.0 & 0.0 & 0.0 & 0.0 & 0.476 \\
\hline Glass Ionomers & 50 & 28.38 & 18.92 & 2.7 & 0 & 0 & 0.283 \\
\hline
\end{tabular}

Table 3: Chi-square, test (Treatments vs gender)

\begin{tabular}{|l|c|c|c|}
\hline \multicolumn{1}{|c|}{ Treatment procedures } & \multicolumn{2}{c|}{ Gender } & \\
\hline Compo-Rest & Female & Male & Chi-square P-value \\
\hline Amalgam-Restoration & 41.61 & 58.39 & 0.333 \\
\hline Extraction & 42.86 & 57.14 & 0.894 \\
\hline Fixed- prosthetic & 40.32 & 59.68 & 0.426 \\
\hline Removable-Prosthetic & 47.27 & 52.73 & 0.476 \\
\hline Fluoride & 37.74 & 62.26 & 0.563 \\
\hline Fissure-Sealants & 46.15 & 53.85 & 0.618 \\
\hline Scaling-Polishing & 46.67 & 53.33 & 0.601 \\
\hline Space- Maintainer & 40.88 & 59.12 & 0.534 \\
\hline Endo-Treatment & 52.78 & 47.22 & 0.224 \\
\hline Pulp-Therapy & 41.48 & 58.52 & 0.872 \\
\hline Stainless Steel Crown & 42.5 & 57.5 & 1.0 \\
\hline Glass Ionomers & 42.42 & 57.58 & 1.0 \\
\hline
\end{tabular}

\section{Discussion}

Oral health care in UAE is delivered mainly by federal Government organizations, non-governmental organizations and private practitioners. Ajman University (AU) is a Nongovernmental organization, contributing to people's oral health, through its dental clinics as part of the studenttraining program. Fourth and third year students, College of Dentistry, AU provide dental treatments to adult and children patients who are usually selected at the through screening process that determines whether the patient is a teaching case for students. The patient who is suitable for a teaching is assigned to a student within a particular group practice. All ages and genders have benefited from free dental services. Most of the treatment provided by the Dental School's clinic is routine dentistry. A qualified dentist or senior staff always supervise students performing clinic treatments. It is generally recognized that the care provided by the teaching clinics is inefficient. However, in the last quarter of the twentieth century, dental school clinics began to pay more attention to how treatment rendered (Formicola 2008). Dental school clinics are becoming more competitive in an effort to provide a solid financial base for the schools addition to their traditional educational mission (Sulski 1995).

Analysis of the result demonstrated a diversity in dental treatments that patients had received. Clinical examinations and restorative treatments were found to be the most common types of provided dental care. This correlates with other studies where graduates felt well prepared in many areas of restorative dentistry (Smith 2010a, Smith 2010b, Perez 2010) and, Yiu CK 2012), that may be linked to the amount of time spent in restorative dentistry as an undergraduate. This is followed by scaling and polishing, extraction and endodontic treatment, pediatric procedures, (including, pulp therapy, stainless steel crown and glass ionomer), preventive treatments (fluoride\& fissure sealants), and prosthetic replacement. These findings reflect the undergraduate clinical training program, in which all types of the routine dental treatments conducted by various departments as a training program for undergraduates. A combination of restorative, endodontic and extraction treatments reflects the extent of teeth damage among the patients. There existed significant association between 
certain dental treatment and age group dominant at age group (6-18) that all these types of treatment either pediatric dental treatment or preventive treatment which both are common at this age group. The significant association between removable prosthetic and age group, dominant at age group (32-44), indicates that this age group suffers loss of teeth that may require more replacement either by partial or complete dentures. The fact that faculty-assisting students in planning and performing various dental treatments led to a measure of criteria standardization. This could be a strength to this study and advantage may not be available outside dental school clinics. Due to different systems and criteria of health service regulations in different countries and lack of any previous study has limited discussion of these findings.

There are some limitations to the present study should be taken into consideration when interpreting the data. First, the data used in this study extracted from the patients' dental record who sought care in dental school clinics in accordance with the training program and might not therefore, be representative of dental offices or other UAE service access. Second, our data were for only Ajman University - Fujairah dental school, so our results are not generalizable to other schools. Others include patients' satisfaction and care outcomes.

\section{Conclusion}

Despite the study limitations, it is important to mention that even in countries where the state finances a larger proportion of dental services, unequal access to care exists and many people admit to having to postpone dentist visits for financial reasons. This study demonstrates the types and amount of dental treatments given free to patients from Fujairah through the Dental School clinic, Ajman University- Fujairah campus. Further large-scale study to assess the quality and patients' satisfaction regarding the treatments rendered by dental schools' clinics is highly recommended.

\section{Acknowledgement}

Extended to AJAMI O. department of Mathematics Ajman University. Fujairah, UAE, for statistical analysis, and to OLA S. General Dentist from College of Dentistry, Ajman, University, Fujairah, UAE, for collecting data from patients' files

\section{Source of Funding}

None.

\section{Presentation at a meeting}

None.

\section{Conflicting of Interest}

None.

\section{References}

1. Ali K, Tredwin C, Kay EJ, Slade A, Pooler J. Preparedness of dental graduates for foundation training: a qualitative study. $\mathrm{Br}$
Dent J 2014;217(3):145-9. doi:

10.1038/sj.bdj.2014.648.PMID: 25104700

2. Ephrem H, Self KD, Blue CM. Introducing and Evaluating Intraprofessional Team-Based Care Delivery in a Dental School Clinic: A Pilot Study. J Dent Educ 2018;82(9):980988. doi: 10.21815/JDE.018.093.PMID: 30173195

3. Formicola AJ, et al 2008; Evolution of dental school clinics as patient care delivery centers. J Dent Educ 2008;72(2):110-27. PMID: 18250387.

4. Nikolovska J. Oral health care provision systems in the black sea countries part 14: the Republic of Macedonia. Oral Health Dent Manage 2013;12(2):61-4. PMID: 23756420

5. Perez FA, Allareddy V, Howell H, Karimbux N. Comparison of clinical productivity of senior dental students in a dental school teaching clinic versus community externship rotations. $J$ Dent Educ 2010;74(10):1125-32. PMID: 20930243

6. Petersen PE (2008) World Health Organization global policy for improvement of oral health--World Health Assembly 2007 Int Dent J 2008;58(3):115-21.PMID: 18630105.

7. Pine CM, Pitts NB, Steele JG, Nunn JN, Treasure E.(2002). Dental restorations in adults in the UK in 1998 and implications for the future. Br Dent J 2001;190(1):4-8.PMID: 11235978.

8. Richard J. Manski I, John F. Moeller. Use of dental services: An analysis of visits, procedures and providers, J Am Dent Assoc 2002;133(2):167-75.

9. Smith M, Lennon MA, Robinson PG. Students' clinical experience on outreach placements. Eur J Dent Educ 2010b;14(1):7-11. doi: 10.1111/j.1600-0579.2009.00582.x. PMID: 20070793.

10. Smith M, Lennon MA, Robinson PG. The Sheffield outreachteaching programme. Br Dent J 2010a;209(10):513-20. DOI: 10.1038/sj.bdj.2010.1038.

11. Sulski J. The future of dental school clinic patient care. $C D S$ Rev 1995;88(7):16-21.PMID: 9528452

12. Tandon $S$. Challenges to the oral health workforce in India. $J$ Dent Educ 2004;68(7):28-33. [PMID]. 15282249

13. Wanyonyi KL, Radford DR, Gallagher JE.(2017) Dental Treatment in a State-Funded Primary Dental Care Facility: Contextual and Individual Predictors of Treatment Need? PLoSOne 2017;12(1):e0169004. doi: 10.1371/journal.pone.0169004. eCollection 2017. PMID: 28118361.

14. Yiu CK, McGrath C, Bridges S, Corbet EF, Botelho MG, Dyson JE, et al. Self-perceived preparedness for dental practice amongst graduates of The University of Hong Kong's integrated PBL dental curriculum. Eur J Dent Educ 2012;16(1):e96-e105.

How to cite this article: Ergieg SM, Warreth A. An analysis of dental treatments rendered by undergradutes at ajman university to patients from fujairah, UAE. Ann Prosthodont Restor Dent 2019;5(3):72-5. 